\title{
Evaluation of the relationship between upper intercanine and inner canthal distances in selected patients
}

\author{
Hamid Neshandar Asli ${ }^{*}$ and Mastooreh Ganjeh Khosravi ${ }^{2}$ \\ ${ }^{1}$ Associate Professor \\ ${ }^{2}$ Dentist Dental Sciences Research Center, Department of Prosthodontics, Faculty of Dentistry, Guilan \\ University of Medical Sciences, Rasht, Iran
}

\begin{abstract}
Esthetics is one of the important treatment goals in prosthetic dentistry. The correct choice of anterior teeth in terms of size and appearance is very effective to the success of the prosthetic treatment. One of the ways to determine the size of the anterior teeth is using facial indices. The aim of this study was to determine the relationship between the upper intercanine width and the inner intercanthal distance. In this cross- sectional study, 114 patients admitted to the Guilan Faculty of Dentistry (62 women and $52 \mathrm{men}$ ), over the age of 18 who were eligible, were randomly selected. Inner intercanthal distance and the distance between the tips of the upper canines were measured with a digital caliper. Data were analyzed using Pearson's correlation coefficient analysis, independent and paired t-test. The mean of intercanthal distance and intercanine width was 30.75 and $34.56 \mathrm{~mm}$, respectively. A significant relationship existed between intercanthal distance and intercanine width. It was found the biometric ratio of 1 to 1.13 could be used to estimate intercanine width. These results could be used as a helpful guide for selection of anterior teeth width in the population of patients. This biometric ratio may not be reliable in women.
\end{abstract}

KEY WORDS: INTERCANTHAL DISTANCE, INTERCANINE WIDTH, ESTHETICS

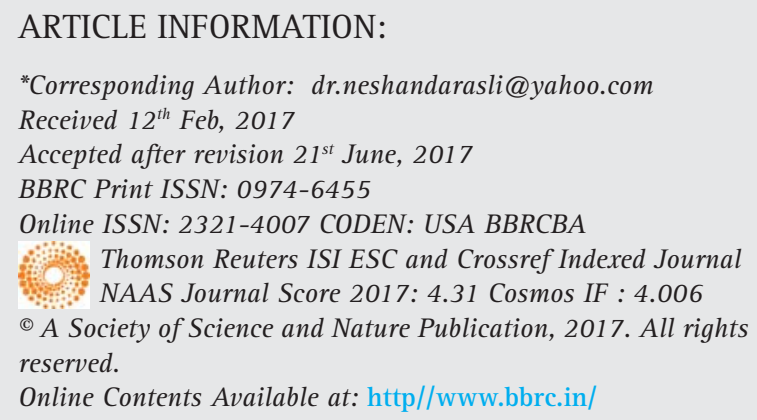




\section{INTRODUCTION}

Esthetics is a primary consideration for patients seeking prosthodontic treatment. The development of new dental materials and techniques has led to a greater number of treatment options that maximize the likelihood of an attractive outcome (Owens et al. 2002). The goal is to have the maxillary anterior teeth restore optimal dentolabial relations in harmony with the overall facial appearance. However, there is little scientific data in the dental literature to use as a guide for defining the proper size and shape of anterior teeth or determining normal relationships for them (Hasanreisoglu et al. 2005).

The eyes, the mouth and the interplay of the muscles of facial expression around these organs telegraph the personality and the moods of the individual. The anterior teeth framed by the lips are the dominant features of the mouth when the components of the oral region of the face and the oral cavity are in harmony that uniquely human gesture, the smile, can be a most pleasing and attractive attribute for a person (Asal et al 2011). An important element of prosthetic treatment of edentulous patients is determination of size, shape and color of artificial anterior teeth that will restore the natural dentolabial harmony, as well as the dentofacial structure disturbed by teeth loss (Strajni et al. 2013).

It is a fact the various methods and indicators were used to determine the size of artificial anterior teeth for edentulous patients but making the right choice is extremely important for both functional and physiognomic rehabilitation of these patients. It is therefore necessary to establish parameters that are as objective as possible in order to achieve optimal occlusion reconstruction in prosthetic treatment of edentulous patients (Baer and Reynolds, 1992).Physiognomic prostethics develop one's ability of observing space and one's sense of plastic restitution, which is necessary for all clinical and technical works (Gonçalveset al. 2009). According to physiognomic standards, the visibility of anterior teeth is determined by their correlation with the upper and the lower lip (Gonçalveset al. 2009). Coincidence between the canine distal aspects and commissures was recorded only within 8\% of both Egyptian and Saudi populations. Additionally, within the Egyptian population, coincidence was recorded only at Class-I ridge relationship (Asal et al 2011). Studies on anthropometric facial characteristics and the jaw complex, as well as studies on their interrelations with natural teeth have given us the knowledge of their mutual individual harmony. A great number of conducted studies on the human face prove the existence of significant variations in parameters among different races, nations and popu- lations, as well as among individuals (Knezovic et al. 2007).

The proper teeth arrangement and occlusal vertical dimension are the key elements contributing to the dento-facial beauty of edentulous patients. In the literature many anthropometric studies have been done to standardize the tooth position in dental arch but most of the studies were concerned for anterior teeth. Scarce studies have examined the scientific methods for determining the positioning of posterior teeth in complete dentures (Debnath et al. 2014). Attempts were done to determine accurate correlation between maxillary anterior teeth, teeth size and face beauty, but scarce information exist on the relationship between the upper intercanine distance and the inner canthal distance and face beauty. For instance, MavrosKouf and Richie (1981) demonstrated some relationship between the nasal width and the intercanine distance which suggested its use to establish the width of the anterior teeth. So, the aim of the current study was to estimate the relationship between the upper intercanine distance and the inner intecanthal distance in selected patients.

\section{MATERIAL AND METHODS}

In this cross- sectional study, 114 patients (62 women and 52 men) admitted to the Guilan Faculty of Dentistry (Rasht, Iran) were selected. The inclusion criteria were over the age of 18, had no asymmetry, disorder or abnormality on eye and eye socket without previous surgery. The age of the patients was between 20-48 years old. Inner intercanthal distance and the distance between the tips of the upper canines were measured with a digital caliper.

\section{STATISTICAL ANALYSIS}

Results are expressed as means $\pm \mathrm{Sd}$. Differences between groups were tested for statistical significance by paired and independent t test, Pearson's correlation coefficient analysis using one-way variance analysis (ANOVA) using SPSS statistical software. $\mathrm{P}<0.05$ were considered to denote significant differences between groups.

\section{RESULTS}

The results of the relationship between the upper intercanine distance and the inner canthal distance in patients are presented in table 1-7. The mean intercanine to intercanthal distance was $1.14 \pm 0.063$ and $1.12 \pm 0.111$ in men and women (table 1). 


\begin{tabular}{|c|c|c|c|}
\hline & $($ Mean \pm Sd) & Min & Max \\
\hline Male & $1.14 \pm 0.063$ & 1.0 & 1.31 \\
\hline Female & $1.12 \pm 0.111$ & 0.9 & 1.47 \\
\hline Total & $1.13 \pm 0.093$ & 0.9 & 1.47 \\
\hline
\end{tabular}

Based on the table 2, the intercanine to intercanthal distance $(\mathrm{mm})$ ratio in patients was $0.89 \pm 0.074$ and the intercanine to intercanthal distance was greater in women $(1.11 \mathrm{~mm})$ compared to the men $(1 \mathrm{~mm})$.

Table 2. the intercanthal to intercanine distance $(\mathrm{mm})$ ratio in patients

\begin{tabular}{|l|l|l|l|}
\hline & $($ Mean \pm Sd $)$ & Min & Max \\
\hline Male & $0.88 \pm 0.048$ & 0.76 & 1 \\
\hline Female & $0.91 \pm 0.088$ & 0.68 & 1.11 \\
\hline Total & $0.89 \pm 0.074$ & 0.68 & 1.11 \\
\hline
\end{tabular}

According to the table 3, there was no significant difference between the distance of the upper canines tips between man and women ( $\mathrm{P}=0.53)$.

\begin{tabular}{|c|c|c|c|}
\hline & $($ Mean $\pm S d)$ & $T$-test & $P$ value \\
\hline Male & $34.93 \pm 1.87$ & 1.926 & 0.053 \\
\hline Female & $34.19 \pm 2.16$ & & \\
\hline
\end{tabular}

Also, no significant difference was detected between the intercanthal distance in patients $(\mathrm{P}=0.543)$ (table 4).

\begin{tabular}{|c|c|c|c|}
\hline & $($ Mean \pm Sd) & $T$-test & $P$ value \\
\hline Male & $30.64 \pm 1.73$ & -0.610 & 0.543 \\
\hline Female & $30.86 \pm 2.55$ & & \\
\hline
\end{tabular}

Significant difference was detected between the distance of the upper canine tips with intercanthal distance in male which the canine distance was $4.23 \mathrm{~mm}$ higher than intercanthal distance $(\mathrm{P}=0.0001)$ (table 5).

Table 5. The comparison of the distance of the upper canines tips with intercanthal $(\mathrm{mm})$ in male

\begin{tabular}{|l|l|l|l|}
\hline & $($ Mean \pm Sd $)$ & Paired $t$ test & P value \\
\hline Intercanthal & $30.61 \pm 1.731$ & -17.157 & $<0.0001$ \\
\hline Canine & $34.93 \pm 1.823$ & & \\
\hline
\end{tabular}

As seen in table 6, significant difference detected between the distance of the upper canines tips with intercanthal distance which the canine distance was $3.33 \mathrm{~mm}$ greater than intercanthal distance $(\mathrm{P}=0.0001)$.

Table 6 . The comparison of the distance of the upper canines tips with intercanthal $(\mathrm{mm})$ in female

\begin{tabular}{|l|l|l|l|} 
& $($ Mean \pm Sd $)$ & Paired $t$ test & P value \\
\hline Intercanthal & $30.86 \pm 2.553$ & -8.363 & $<0.0001$ \\
\hline Canine & $34.19 \pm 2.158$ & & \\
\hline
\end{tabular}

A significant correlation was detected between the upper canines tips with the intercanthal distance $(\mathrm{mm})$ in patients $(\mathrm{P}=0.014)$ where by increasing in the intercanthal distance, the upper canines tips significantly increased in men $(\mathrm{P}=0.000)$ than women $(\mathrm{P}=0.333)$ (table 7).

\begin{tabular}{|c|c|c|}
\hline Patients & $\mathrm{R}$ square & $\mathrm{P}$-value \\
\hline Male & 0.495 & 0.000 \\
\hline Female & 0.125 & 0.333 \\
\hline Total & 0.231 & 0.014 \\
\hline
\end{tabular}

\section{DISCUSSION}

Facial attractiveness is a factor in many important social interactions. A number of studies have found that facial attractiveness is related to how humans perceive others (Ahila et al. 2014). The development of new dental materials and techniques has led to a greater number of treatment options that maximize the likelihood of an attractive outcome. Toward this end, the size and form of the maxillary anterior teeth are important not only to dental esthetics, but also to facial esthetics. The goal is to have the maxillary anterior teeth restore optimal dento-labial relations in harmony with the overall facial appearance (Ahila et al. 2014). As observed in this study, the mean of intercanthal distance and intercanine width was 30.75 and $34.56 \mathrm{~mm}$, respectively.

A significant relationship was detected between intercanthal distance and intercanine width. It was found that the biometric ratio of 1 to 1.13 could be used to estimate intercanine width. Ideal arrangement of teeth for an edentulous patient becomes difficult in the absence of pre-extraction records. Various methods have been adopted for the ideal arrangement of teeth most of them reveals a dependence on the physical characteristics of the dento-facial landmarks such as Inter-alar width, Bi-zygomatic width and Facial heights. Beside these, 
various intra oral landmarks like Incisive papilla and Inter-canine distance have also been taken into consideration for selection and arrangement of teeth (Debnath et al. 2014). Also, Wehner et al (1967) who suggested extending parallel lines from the lateral surfaces of the ala of the nose onto the labial surface of the maxillary occlusion rim to estimate the inter-canine cusp tip. Scandrett (1982) also reported a significant correlation between the interalar width and the width of maxillary anterior teeth.

The sex related correlation reported for gender and reliability of the face biometric index, however, controversial reports exist. For instance there was no correlation between facial measurement for neither the population as a whole nor when the population was divided into sex and race. There was a correlation between facial and teeth measurements in women while no correlation was found in men (Al-el-Sheikh and Al-Athel, 1998). In our study, we found this biometric ratio may not be reliable in women. We think that further research is needed to determine accuracy of the observed results.

In a study by Bonakdarchian and Ghorbanipour (2010) about the relationship between interalar width, intercanine tip distance, and denture teeth size reported, mean and standard deviation values for interalar width, intercanine tip distance and the width of anterior maxillary teeth were $36.38 \pm 3.81,34.15 \pm 2.05$, and $48.23 \pm$ $2.068 \mathrm{~mm}$, respectively. There were significant relations between interalar width, intercanine tip distance and widths of the six anterior teeth. Dimensions seem to be greater in men. It seems the use of interalar width can provide a more reliable predictive equation for tooth size (Bonakdarchian and Ghorbanipour, 2010). It is reported the innercanthal distance and interalar width cannot be used as a preliminary method for determining the width of the maxillary anterior teeth for edentulous patients (Deogade et al. 2015).

Various modalities have been suggested for selecting the size of the anterior teeth like inter-alar distance, inter-canthal distance, bi-zygomatic width, intercanine width. However there is no reliable method for selection of anterior teeth and etc (Ahila et al. 2014). Patients receiving their first dentures often expect to appear similar to when they had their natural teeth. Therefore, the correct selection of the artificial teeth is essential to achieve a pleasant esthetic outcome. If some natural teeth are remained, it is easier to choose artificial teeth that blend with the natural dentition than to choose teeth for the edentulous patient with no pre-extraction records available (Ahila et al. 2014). It is reported, canines tend to exhibit the greatest gender-based morphological difference compared to other tooth groups (Berksun et al. 2002). Inter-canine width method is based on the hypothesis that the maxillary canines' distal aspects should be located approximately at the commissures of the month (Asal et al 2011). Gender variations in the dimension of anterior teeth for most racial with men exhibiting wider anterior teeth than women with the canines showing the greatest gender variation (Hasanreisoglu et al., 2005) i.e. for men, the canines distal aspects are distal to commissures. Moreover, Arja et al. (1974) reported some gender differences; meanwhile the significant difference was recorded between all males at ridge relationships. It is suggested the innercanthal distance may be a reliable predictor of the width of the maxillary central incisors. Interpretation and extrapolation of the results must be tempered, however, by an acknowledgement of the study's limitations. The innercanthal distance should be used only as a reference value in estimations of central incisor width (Reddy et al. 2014). In conclusion, these results could be used as a helpful guide for selection of the anterior teeth width in the population of patients. This biometric ratio may not be reliable in women.

\section{REFERENCES}

Ahila SC, Vaishnavi P, Muthu Kumar B.(2014) Comparative evaluation of maxillary and mandibular anterior teeth width with the length of index and little finger. J Indian Prosthodont Soc (July-Sept 2014) 14(3):215-218

Al-el-Sheikh HM, Al-Athel MS. (1998)The relationship of interalar width, interpupillary width and maxillary anterior teeth width in Saudi population. Odontostomatol Trop. 1998;21(84):7-10.

Arja, B.S., Savara, B.S., Thomas, D., et al., 1974. Relation of sex and occlusion to mesiodistal tooth size. Am. J. Orthod. 66, 479-486.

Asal S, Al-Shehri SA, Rashad HMA.2011Canine location in different maxillomandibular relationships in Egyptians and Saudis. The Saudi Dental Journal 23, 37-42

Baer ML, Reynolds MA.1992 Comparison of anterior tooth width in natural and artificial dentitions. J Prosthodon 1992; 1: 84-7.

Berksun S, Hasanreisoglu U, Gokdeniz B. 2002 Computerbased evaluation of gender identification and morphologic classification of tooth face and arch forms. J Prosthet Dent ;88:578-84

Bonakdarchian M, Ghorbanipour R. 2010 Study on the relationship between interalar width, intercanine tip distance, and denture teeth size. Journal of Isfahan Dental School 6(3): 207213.

Debnath N, Gupta R, Meenakshi A, kumar S, Dahota S, Rawat P. 2014 Relationship of inter-condylar distance with inter-dental distance of maxillary arch and occlusal vertical dimension: a clinical anthropometric study. Journal of Clinical and Diagnostic Research, Vol-8(12): ZC39-ZC43

Deogade SC, Mantri SS, Sumathi K, Rajoriya S.2015. The relationship between innercanthal dimension and interalar width 
to the intercanine width of maxillary anterior teeth in central Indian population. The Journal of Indian Prosthodontic Society. 15(2): 91-97.

Gonçalves LC, Gomes VL, De Lima Lucas B, Monteiro SB. 2009. Correlation between the individual and the combined width of the six maxillary anterior teeth. J Esthet Restor Dent 21(3): 182-91.

Hasanreisoglu U, Berksun S, Aras K, Arslan I. 2005. An analysis of maxillary anterior teeth: Facial and dental proportions. J Prosthet Dent 94:530-8.

Knezovic Zlataric D, Kristek E, Celebic A.2007. Analysis of width/length ratios of normal clinical crowns of the maxillary anterior dentition: correlation between dental proportions and facial measurements. Int J Prosthodont 20(3): 313-7.

Mavroskoufis I., Ritchie G.M., 1981. Nasal width and incisive papilla as guide for the selection and arrangement of maxillary anterior teeth. J. Prosthet. Dent., 45:592-597.
Owens EG, Goodacre JC, Loh PL, Hanke G, Okamura M, Jo K. 2002. A multicenter interracial study of facial appearance. Part 2: a comparison of intraoral parameters. Int J Prosthodont 15:283-8

Reddy N, Singh T R, Reddy S, Guruprasad Y. 2014. A cross-sectional clinical study on shape of nose inner-canthal distance and geometric progression as predictors for width of the maxillary incisor teeth. Journal of Natural Science, Biology and Medicine. 5(2): 265- 267

Scandrett, F.R., Kerber, P.E. Umrigar, Z.R.1982. A clinical evaluation of techniques to determine the combined width of the maxillary anterior teeth and the maxillary central incisor. 48:15-22.

Strajni L, Vuleti I, Vuini P. 2013. The significance of biometric parameters in determining anterior teeth width. Vojnosanit Pregl 70(7): 653-659.

Wehner, P.J., Hickey, J.C. Boucher, C.0. 1967 Selection of artificial teeth. J. Prosthet. Dent. 18:222. 